\title{
The removal of "pre-authorization" and patients' free movement in cross-region healthcare services: evidence from China
}

\author{
Zhengyuan Xu1, Wei Xu', Michael Matalimanja \\ 1 School of International Pharmaceutical Business, China Pharmaceutical University, Nanjing, China \\ Keywords: patient mobility, cross-region healthcare, pre-authorization, medical expenditure \\ https://doi.org/10.29392/001c.30792
}

Journal of Global Health Reports

Vol. 5, 2021

\begin{abstract}
Background
The record-filing process in China's cross-region healthcare is similar to the "pre-authorization" in the EU, which is the requirement for patients to seek healthcare services outside the affiliated regions. Policymakers are increasingly designing policies that encourage patient choice and giving them the freedom to choose healthcare providers without "pre-authorization". Some pilot regions in China tried to provide patients with the freedom to choose healthcare services freely without a record-filing process. This study aims to evaluate the effects of the removal of the record-filing process and to provide pieces of evidence for policy decisions on the cross-region healthcare system.
\end{abstract}

\section{Methods}

In this study, a difference-in-difference model that controlled for potential confounding was applied to ascertain the changes in cross-region inpatient visits, medical expenditures, health insurance payments and medical cost per-visit following the removal of the record-filing process by using cross-region inpatient claim data in the reform region and nonreform region after the policy intervention.

\section{Results}

The number of cross-region inpatient visits and total medical expenditures of cross-region healthcare costs increased significantly by $40.93 \%(P=0.010)$ and $32.41 \%(P=0.005)$, respectively. Total health insurance payments increased by $3.83 \%$ and were not significant $(P=0.693)$. The average medical cost per visit for cross-region patients in the treated group was $6.44 \%$ lower than that in the control group, also not significantly $(P=0.162)$.

\section{Conclusions}

The findings suggest that giving patients freedom without a "policy barrier" could significantly encourage more patients to seek healthcare services outside the affiliated regions and increase the total medical expenditures. While the financial concerns of the health insurance funds could be reduced effectively if a higher co-payment was used for cross-region patients.

Cross-border healthcare means that the patient physically moved temporarily or occasionally to another region and be treated by healthcare providers in that region than the one in which he is socially insured. ${ }^{1,2}$ It has become a more prominent phenomenon all over the world. In China, cross-region healthcare was referred to as a tendency in which citizens insured on the current national insurance scheme seek healthcare services from medical institutions outside their affiliated regions. Notably, China's health insurance system is characterized by regionalized management at the provincial or municipal level and having different medical resource allocations from region to region. Since the medical resources are mainly concentrated in re- gions with higher levels of economic development, the contradictions between regionalized health insurance schemes and the imbalanced distribution of medical resources reduce the accessibility and fairness of insured persons to seek medical treatment outside the region of residence or affiliation. Since patient mobility is gradually increasing in China, cross-region healthcare has become the core content of China's health system reform.

Relatedly, China and the European Union have a similar classification of cross-border or cross-region healthcare patients. ${ }^{3}$ There are mainly 4 types of patients' movements within the whole country: (i) people retiring from their jobs, mainly senior citizens relocating from the places they were 
affiliated to other regions, ${ }^{4}$ (ii) citizens living in other places for a long time due to education or personal reasons, consequently benefiting from medical care there, ${ }^{5}$ (iii) Employees working in other regions within a short period due to work demands, ${ }^{6}$ (iv) Planned healthcare or medical referral, 7,8 these people are typically to receive medical treatment that is more affordable or considered to be of better quality than in their home region.

China has thus far seen three main developmental processes of cross-region healthcare reimbursement. In the first stage, patients who are hospitalized in other regions must first pay all medical expenses themselves and then return to the region of affiliation with invoices for reimbursement. From 2009 to 2015, the Chinese government embarked on a second stage in which the immediate settlement of medical expenses across different regions was implemented within the province. Patients only needed to pay part of medical expenses with the co-insurance plan upon being discharged from the hospital. The third stage denotes the period from 2015 to the present, patients are enabled to freely select healthcare providers nationwide and all medical expenses can be immediately reimbursed as long as they finished the record-filing procedure in advance. The statistics from National Healthcare Security Administration (NHSA) showed that the annual amount of cross-region healthcare expenditures increased consecutively since the immediate settlement policy was implemented. In 2018, the amount was 1.32 million, 6.3 times of that in 2017. While in 2019, the number increased to 2.72 million. ${ }^{9}$

It can be seen that the record-filing process is the prerequisite in realizing the immediate settlement of cross-region inpatient medical expenses in the current healthcare system. The key part of the immediate settlement policy is centered on a successful record-filing process ${ }^{10}$ (Figure 1). The "record-filing" in China's cross-region healthcare system is similar to the "pre-authorization" 11 for the cross-border healthcare regulation in some countries in the EU where pre-authorization is required for at least one-night hospital stay. In Poland, the strict "pre-authorization" is considered as a "policy barrier" to freedom to receive healthcare services out of affiliated regions, ${ }^{12-14}$ which discourages patients from seeking medical treatment in other regions. ${ }^{11}$ The purpose is to improve the rationality of cross-region healthcare services and avoid the risk of instability that patients' free movement may cause to medical health systems and medical insurance funds in regions of affiliation. ${ }^{15}$ Thus, a "record-filing" or "pre-authorization" policy is regarded as an effective tool to balance the interests of the patients and the financial interests of the health insurance system. ${ }^{16}$

However, the inconvenient and strict record-filing process has always been questioned to decrease patient welfare due to its ability to hinder access to remote medical treatment. ${ }^{17}$ Should policymakers remove the "policy barrier" to give patients the freedom to choose the medical services provider nationwide, which means patients could move freely to seek medical services and get reimbursed immediately without advanced pre-authorization? What are the probable effects of the patients' free movement? Some studies have shown that the total number of patients seeking healthcare services outside the affiliated region and the budget burden on the health insurance funds would increase. Based on data from the Ministry of Health in Poland, ${ }^{12} 81 \%$ of the cross-border application were for the reimbursement of cataract surgery, which was a type of day surgery and did not require a pre-authorization. T. Kostera (2008) ${ }^{18}$ believes that the free movement of patients poses a significant financial risk to regions of residence or affiliation. Requejo (2011) ${ }^{19}$ points out that unlimited demand for cross-border medical treatment leads to the fiscal crisis of medical insurance funds and seriously affects the signing of contracts with medical institutions in regions of affiliation, especially in patient-exporting regions. Peeters $(2012)^{2}$ finds that free patient mobility was expensive as the sickness fund pays the same amount whether patients seek out-of-region medical treatment. On the contrary, Dawson et al. (2006) ${ }^{20}$ reported that increased patient choice does not necessarily stimulate the potential demand of patients to seek medical treatment in other regions. Dimitrios et al. (2013) ${ }^{1}$ showed that free movement of patients can provide faster alternative access to care and increase patient welfare. Andricus and Tang $(2014)^{21}$ believed that cross-border patient mobility reduces the costs for reimbursement.

The current studies have mostly addressed the possible impact of patients' free movement on the theoretical level, lacking empirical evidence. Thus, this study intends to answer the above questions based on evidence in China and consider the implications for policy decisions on the crossregion healthcare scheme. In this article, we performed a difference-in-difference analysis using the hospitalization claim data of urban employee basic medical insurance in Wuxi and Nantong City, Jiangsu Province of China, to evaluate the effects of patient's free movement on the total number of cross-region patients, the total medical expenditures and health insurance funds.

\section{METHODS}

Wuxi and Nantong are cities located in Jiangsu Province and both very close to Shanghai, where most high-quality medical resources are concentrated in the eastern part of China along the Yangtze River Delta. Wuxi, a pilot region with a population of 6.67 million, announced to give patients the freedom to choose healthcare providers freely nationwide without record-filing process since the fourth quarter of 2017 and all medical expenses could be reimbursed immediately when patients were discharged from hospitals. While the record-filing process is required for patients insured in Nantong to seek healthcare services in other regions, otherwise the expenses are not paid by social health insurance. Thus, Wuxi was selected as the treated group (the "reform city") and Nantong as the control group (the "nonreform city"). The GDP growth rate, patient-importing regions, and the number of cross-region inpatient visits were selected as indicators measuring similarities between the treated group and the control group (Table 1).

To exclude the effect of the increase in the number of out-of-region inpatient visits due to urban and rural integration on the evaluation results, this study used the inpatient claims data of urban employee basic medical insurance participants to evaluate the effects of patient's free movement. Given the aim of this study was to explore the 
Table 1. Indicators comparing two cities

\begin{tabular}{|c|c|c|c|c|c|}
\hline \multirow{2}{*}{ Year } & \multicolumn{2}{|c|}{ GDP growth rate (\%) } & Patient-importing regions & \multicolumn{2}{|c|}{ Number of cross-region inpatient visits (million) } \\
\hline & Wuxi & Nantong & Wuxi $\quad$ Nantong & Wuxi & Nantong \\
\hline 2016 & $8.12 \%$ & $9.16 \%$ & \multirow{3}{*}{$\begin{array}{c}\text { Nanjing } 、 \text { Suzhou } \\
\text { Shanghai }\end{array}$} & \multirow{3}{*}{104.34} & \multirow{3}{*}{117.83} \\
\hline 2017 & $7.4 \%$ & $7.8 \%$ & & & \\
\hline 2018 & $8.82 \%$ & $8.95 \%$ & & & \\
\hline
\end{tabular}

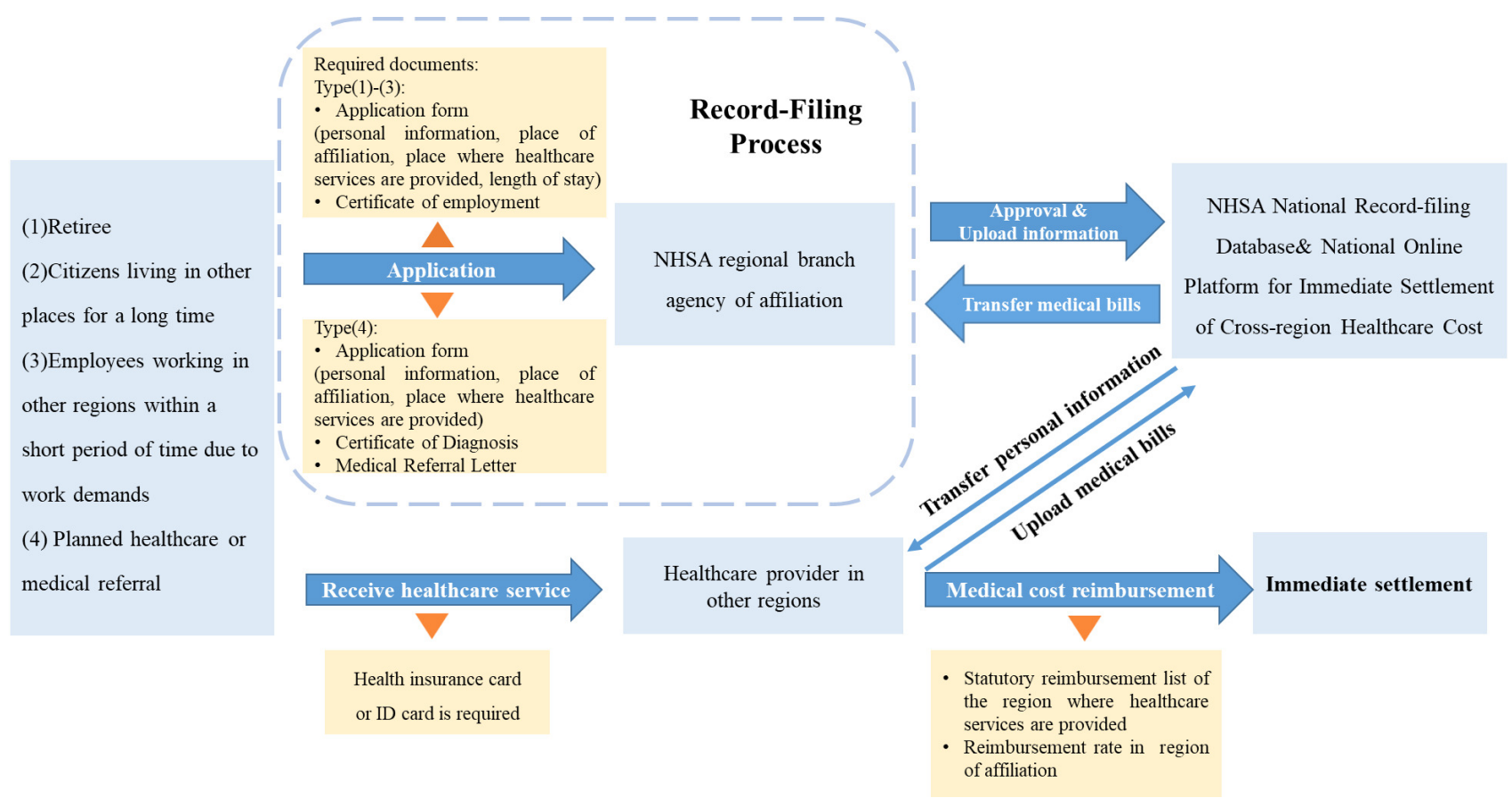

Figure 1. Process for immediate settlement of cross-region healthcare cost in China.

changes in the total number of cross-region patient visits, the total amount of medical expenditure, and health insurance funds after reform, we depended on information from two sources. The summary data recorded the total number of cross-region inpatient visits, total medical expenditures, and the total amount of health insurance funds in each quarter. The person-level sample data included data on length of stay, disease categories (ICD-10), medical institutions classification, region of affiliation, place of treatment provided, the type of cross-region patient, medical costs, and health insurance payments, which were defined as main covariates. We used inpatient claims data from the pre-intervention time from the first quarter of 2016 to the third quarter of 2017 and the post-intervention time from the first quarter of 2018 to the fourth quarter of 2018 as the policy of patient's free movement was introduced at the beginning of the fourth quarter of 2017 in Wuxi.

Our study approach was to pool data from the abovementioned 12 quarters and to estimate the effect of patient's free movement by comparing the changes on outcome variables before and after the intervention using a difference-in-difference (DID) approach, which allows us to calculate the average impact of the reform. We first used stepwise regression to select independent variables. To estimate DID, pooled ordinary least squares (pooled OLS) regression was exploited. The estimating equation has the following form:

$$
\begin{array}{r}
Y_{i t}=\beta_{0}+\beta_{1} T_{i}+\beta_{2} P_{t}+\beta_{3} T_{i} P_{t}+\beta_{4} X_{i t}+\varepsilon_{i} \\
(t=0,1 ; i=1, \ldots, n)
\end{array}
$$

where, $Y_{i t}$ are the outcome variables representing the total number of cross-region inpatient visits, total medial expenditures of cross-region patients, the total amount of health insurance payments, and medical cost per visit; $\beta_{0}-\beta_{4}$ are unknown parameters, $\beta_{0}$ is a constant term; $T_{i}$ is the treatment vector indicating whether the region $\mathrm{i}$ is subject to the intervention. The treated group is 1 , and the control group is $0 . P_{t}$ indicates the occurrence of the intervention in period t. The interaction term $T_{i} P_{t}$ denotes the difference after the policy of patient's free movement came into effect. $\beta_{3}$ is the coefficient on the interaction term reflecting the true effect of treatment. If $\beta_{3}$ is negative, the influence is negative, and vice versa. $\varepsilon_{i}$ is a random error. The vector $X_{i t}$ represents a variety of controlled variables, which are the average length of stay, principal diagnosis, the propor- 

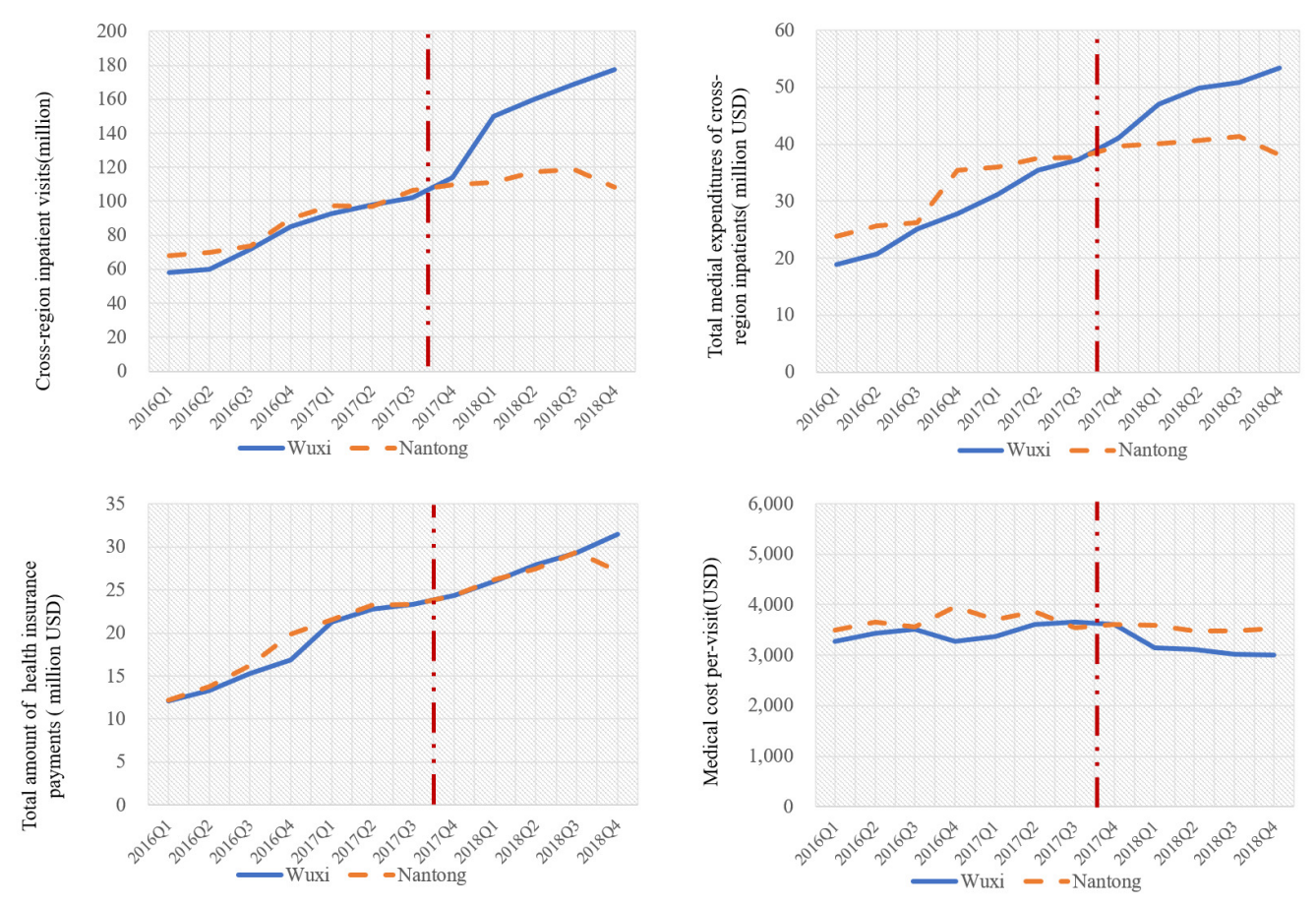

Figure 2. Trends in the number of cross-region inpatient visits, total medical expenditures, total amount of health insurance payments, and medical cost per-visit after the intervention.

tion of inpatient visits in tertiary medical institutions, the proportion of patients exported to Shanghai, the proportion of retirees, the proportion of medical referral patients, and co-payment rate. In this study, we took the natural logarithm of the outcome variables and used a semilogarithmic regression equation for estimating the impact of patients' free movement. All data were processed by STATA (Release 16. College Station, TX: StataCorp LLC)

\section{RESULTS}

\section{DESCRIPTIVE STATISTICS OF CHANGES IN OUTCOME VARIABLES AFTER THE INTERVENTION}

The change over time in the outcome variables for the intervention group, compared to the change over time for the control group are depicted in Figure 2, showing the trend in cross-region patient visits, total medical expenditures of cross-region patients, total health insurance payments and medical cost per-visit in Wuxi and Nantong between the 2016Q1 and the 2018Q4.

The average number of inpatient visits in Wuxi before the policy intervention from the first quarter of 2016 to the third quarter of 2017 was 81.02 million. The total medical expenditures of cross-region patients and total health insurance payments in Wuxi were CNY182.50 million (US\$28.08 million) and CNY115.89 million (US\$17.83 million) respectively. While from the first quarter of 2018 to the fourth quarter of 2018, the number of inpatient visits was 163.87 million and the total medical cost and health insurance payments were CNY326.71 million (US\$50.72 million) and CNY184.41 million (US\$28.67 million), representing a $102.26 \%, 79.89 \%$ and $60.85 \%$ increase respectively.

By contrast, the cross-region inpatient visits, medical ex- penses and the amount of health insurance payments in Nantong increased by $32.42 \%, 26.13 \%$ and $48.36 \%$ after the intervention, which were lower than that in the treated group. In addition, the above-mentioned variables in the treated group were higher than that in the control group in the same period after the policy intervention by $1.45,1.25$ and 1.04 times respectively. Moreover, the average medical cost per visit of out-of-town inpatients in Wuxi decreased from CNY22,400(US\$3446.15) to CNY19,900(US\$3061.54), displaying a decrease by $10.97 \%$ after the reform occurred. Similarly, Nantong experienced a decline from CNY23,900 (US\$3676.92) to CNY22,800(US\$3507.69). The medical cost per visit of cross-region inpatients in the control group was 1.14 times higher than that in the treatment group in the same period after the policy intervention.

\section{REGRESSION RESULTS}

Table 2-5 reported the regression results on the effect of policy intervention on each outcome variable. Models (1)(8) represent regressions in which additional control variables are added step by step. Since we used a semilogarithmic regression equation for estimating the impact of the intervention on outcomes, this impact was calculated as follows: $e^{\beta}-1 .{ }^{22,23}$ Heteroscedasticity robust standard error was used to estimate the significance of coefficients. $\mathrm{R}^{2}$ showed that the goodness of fit of the model is high.

It is worth noting, the regression results reported in Table 2 showed a positive predictive on the interaction term, indicating a significant increase in the number of cross-region inpatient visits after the intervention. In addition, the results of model (6) denoted an increase of $40.93 \%$ $\left(e^{0.3431}-1\right)$ in cross-region inpatient visits after controlling 
Table 2. Regression results on the effect of policy intervention on total cross-region inpatient visits

\begin{tabular}{|c|c|c|c|c|c|c|}
\hline Variables & (1) & (2) & (3) & (4) & (5) & (6) \\
\hline Treat & $\begin{array}{l}-0.0681^{* *} \\
(-2.77)\end{array}$ & $\begin{array}{l}-0.0915^{* *} \\
(-2.40)\end{array}$ & $\begin{array}{l}-0.0675 \\
(-1.41)\end{array}$ & $\begin{array}{l}-0.1095 \\
(-1.74)\end{array}$ & $\begin{array}{c}-0.1436 \\
(-1.73)\end{array}$ & $\begin{array}{l}-0.2842 \\
(-1.50)\end{array}$ \\
\hline Post & $\begin{array}{l}0.6323^{* * *} \\
\quad(9.11)\end{array}$ & $\begin{array}{l}0.5244^{* * *} \\
(3.35)\end{array}$ & $\begin{array}{l}0.5406^{* *} \\
(3.26)\end{array}$ & $\begin{array}{l}0.4864^{* *} \\
(2.68)\end{array}$ & $\begin{array}{l}0.6298 \\
(2.89)\end{array}$ & $\begin{array}{l}0.7233^{* *} \\
(2.80)\end{array}$ \\
\hline Treat*Post & $\begin{array}{c}0.3655 \\
* * * \\
(4.79)\end{array}$ & $\begin{array}{l}0.3578^{* * *} \\
(4.66)\end{array}$ & $\begin{array}{c}0.3409^{* * *} \\
(4.14)\end{array}$ & $\begin{array}{c}0.3302^{* * *} \\
(3.93)\end{array}$ & $\begin{array}{c}0.3096^{* *} \\
(3.10)\end{array}$ & $\begin{array}{c}0.3431^{* *} \\
(4.01)\end{array}$ \\
\hline Length of stay & - & $\begin{array}{l}0.0297 \\
(0.85)\end{array}$ & $\begin{array}{l}0.0291 \\
(0.78)\end{array}$ & $\begin{array}{l}0.0316 \\
(0.82)\end{array}$ & $\begin{array}{l}0.0411 \\
(0.90)\end{array}$ & $\begin{array}{l}0.0422 \\
(0.98)\end{array}$ \\
\hline Disease category & - & - & $\begin{array}{l}-0.1393 \\
(-1.03)\end{array}$ & $\begin{array}{l}-0.0130 \\
(-0.08)\end{array}$ & $\begin{array}{l}0.0568 \\
(0.28)\end{array}$ & $\begin{array}{l}-0.0929 \\
(-0.27)\end{array}$ \\
\hline $\begin{array}{l}\text { Proportion of inpatients in tertiary } \\
\text { medical institutions }\end{array}$ & - & - & - & $\begin{array}{l}-0.7848 \\
(-1.74)\end{array}$ & $\begin{array}{c}-0.7955 \\
(-1.37)\end{array}$ & $\begin{array}{c}-1.3059 \\
(-1.03)\end{array}$ \\
\hline $\begin{array}{l}\text { Proportion of patients exported to } \\
\text { Shanghai }\end{array}$ & - & - & - & - & $\begin{array}{c}-0.3137 \\
(-0.99)\end{array}$ & $\begin{array}{r}-0.7017 \\
(-1.21)\end{array}$ \\
\hline Proportion of retirees & - & - & - & - & - & $\begin{array}{r}-0.6087 \\
(-1.10)\end{array}$ \\
\hline $\mathrm{R}^{2}$ & 0.9692 & 0.9712 & 0.9718 & 0.9734 & $0 \cdot 9753$ & 0.9794 \\
\hline
\end{tabular}

Note: $t$ statistics are shown in parenthesis, ${ }^{* * * * * * * * *}$ represent significant at the confidence level of $5 \%$ and $1 \%$ respectively. The same as below

for other variables, with a strong statistical significance $(P$ $=0.010$ ).

In particular, Table 3 showed that whether other factors are controlled for or not, the policy reform has a significant positive effect on the total medical cost. According to the regression results of model (6), the coefficient of interaction term Treat*Post was 0.2807 , which was significant $(P$ $=0.005$ ), and showed an increase in total medical expenditures of cross-region inpatients by $32.41 \%$. According to the results of model (6) shown in Table 4 , the medical cost pervisit of cross-region inpatients reduced by about $6.44 \%$ after the intervention, but the effect was not statistically significant $(P=0.162)$. Then, the regression analysis results in Table 5 exhibited an increase of about $3.83 \%$ in the total amount of health insurance payments with all other relative vectors were controlled for, which was not significant $(P=0.693)$. In addition, disease type and the proportion of retirees have an obvious impact on health insurance payments. The higher the proportion of cross-region patients with malignant tumors and retirees were, the more the health insurance funds spent.

At last, this research conducted a robustness check on the results by selecting the data from the first quarter of 2016 to the third quarter of 2017 for Wuxi and Nantong, assuming that the policy reform occurred in the fourth quarter of 2016, and estimated the changes in above mentioned four outcome variables. The results in Table 6 , showed no significant effects of patient's free movement on inpatient visits, medical expenditures, health insurance fund and medical cost per visit. This confirms that the regression results of the DID model robustness and strong explanatory significance in estimating the effect of removing the "policy barrier".

\section{DISCUSSION}

In this study, we examined the changes in cross-region inpatient visits, medical expenditures, health insurance payments, and medical cost per-visit following the removal of the record-filing process-a key process in the cross-region health cost reimbursement using data from the National Online Platform for Immediate Settlement of Cross-region Healthcare Cost in Wuxi and Nantong. Wuxi city has implemented the removal of the "record-filing" process in immediate settlement of cross-region healthcare costs, which indicated the patients' free movement in seeking healthcare services and all medical expenditures could be reimbursed according to the regulation of Wuxi. We developed a difference-in-difference (DID) framework by using Wuxi as a treated group and Nantong as a control group. The increase in the number of cross-region inpatient visits and total medical expenditures was significant, while a positive but insignificant impact on the total amount of health insurance payments. However, the average medical cost per visit for cross-region patients in the treated group was lower than that for cross-region patients in the control group after the intervention, also not significantly. The findings indicated that the removal of the "policy barrier" significantly increased patient mobility and total medical costs while the amount of health insurance payments and medical cost per visit were not affected. In terms of increasing patient mobility, our estimation result is consistent with that of Mckee and Belcher (2008). ${ }^{24}$ 
Table 3. Regression results on the effect of policy intervention on total medical expenditures

\begin{tabular}{|c|c|c|c|c|c|c|}
\hline Variables & (1) & (2) & (3) & (4) & (5) & (6) \\
\hline Treat & $\begin{array}{c}-0.1338^{* * *} \\
(-3.59)\end{array}$ & $\begin{array}{c}-0.1419^{* *} \\
(-2.91)\end{array}$ & $\begin{array}{c}-3154.711 \\
(-1.89)\end{array}$ & $\begin{array}{l}-0.1942 \\
(-2.08)\end{array}$ & $\begin{array}{c}-0.2612^{* *} \\
(-3.35)\end{array}$ & $\begin{array}{c}-0.3197 \\
(-2.20)\end{array}$ \\
\hline Post & $\begin{array}{c}0.6087^{* * *} \\
(10.19)\end{array}$ & $\begin{array}{l}0.5715^{* * *} \\
(4.17)\end{array}$ & $\begin{array}{c}0.5708^{* *} \\
(2.57)\end{array}$ & $\begin{array}{c}0.5045^{* *} \\
(3.06)\end{array}$ & $\begin{array}{l}0.7857^{* * *} \\
\quad(5.50)\end{array}$ & $\begin{array}{l}0.8247^{* * *} \\
(5.05)\end{array}$ \\
\hline Treat*Post & $\begin{array}{l}0.3223^{* * *} \\
(5.39)\end{array}$ & $\begin{array}{l}0.3196^{* * *} \\
(5.40)\end{array}$ & $\begin{array}{l}0.3203^{* * *} \\
(4.05)\end{array}$ & $\begin{array}{c}0.3073^{* * *} \\
(3.92)\end{array}$ & $\begin{array}{l}0.2667^{* * *} \\
(4.56)\end{array}$ & $\begin{array}{l}0.2807^{* * *} \\
(4.84)\end{array}$ \\
\hline Length of stay & - & $\begin{array}{l}0.0102 \\
(0.34)\end{array}$ & $\begin{array}{l}0.0102 \\
(0.32)\end{array}$ & $0.0132(0.41)$ & $\begin{array}{l}0.0319 \\
(0.95)\end{array}$ & $\begin{array}{l}0.0324 \\
(0.94)\end{array}$ \\
\hline Disease category & - & - & $\begin{array}{l}0.0051 \\
(0.02)\end{array}$ & $\begin{array}{l}0.1597 \\
(0.44)\end{array}$ & $\begin{array}{l}0.2969 \\
(0.90)\end{array}$ & $\begin{array}{l}0.2345 \\
(0.54)\end{array}$ \\
\hline $\begin{array}{l}\text { Proportion of inpatients in } \\
\text { tertiary medical } \\
\text { institutions }\end{array}$ & - & - & - & $\begin{array}{l}-0.9604 \\
(-2.51)\end{array}$ & $\begin{array}{c}-0.9814 \\
(-1.68)\end{array}$ & $\begin{array}{c}-1.1943 \\
(-1.20)\end{array}$ \\
\hline $\begin{array}{l}\text { Proportion of patients } \\
\text { exported to Shanghai }\end{array}$ & - & - & - & - & $\begin{array}{c}-0.6153 \\
(-3.16)\end{array}$ & $\begin{array}{c}-0.7771 \\
(-2.13)\end{array}$ \\
\hline Proportion of retirees & - & - & - & - & - & $\begin{array}{l}-0.2537 \\
(-0.52)\end{array}$ \\
\hline $\mathrm{R}^{2}$ & 0.9718 & 0.9721 & 0.9721 & 0.9750 & 0.9835 & 0.9843 \\
\hline
\end{tabular}

Table 4. Regression results on the effect of policy intervention on medical cost per-visit

\begin{tabular}{|c|c|c|c|c|c|c|}
\hline Variables & (1) & (2) & (3) & (4) & (5) & (6) \\
\hline Treat & $\begin{array}{l}-0.0657 \\
(-2.54)\end{array}$ & $\begin{array}{c}-0.0504 \\
(-1.85)\end{array}$ & $\begin{array}{l}-0.0753 \\
(-1.36)\end{array}$ & $\begin{array}{l}-0.0847 \\
(-1.38)\end{array}$ & $\begin{array}{c}-0.1175 \\
(-2.29)\end{array}$ & $\begin{array}{l}-0.0355 \\
(-0.38)\end{array}$ \\
\hline Post & $\begin{array}{l}-0.0236 \\
(-0.88)\end{array}$ & $\begin{array}{c}0.0470 \\
(0.79)\end{array}$ & $\begin{array}{l}0.0302 \\
(0.39)\end{array}$ & $\begin{array}{l}0.0181 \\
(0.21)\end{array}$ & $\begin{array}{l}0.1558 \\
(1.39)\end{array}$ & $\begin{array}{c}0.1014 \\
(0.82)\end{array}$ \\
\hline Treat*Post & $\begin{array}{l}-0.0432 \\
(-1.13)\end{array}$ & $\begin{array}{l}-0.0381 \\
(-0.95)\end{array}$ & $\begin{array}{l}-0.0206 \\
(-0.39)\end{array}$ & $\begin{array}{l}-0.0230 \\
(-0.41)\end{array}$ & $\begin{array}{c}-0.0428 \\
(-0.79)\end{array}$ & $\begin{array}{l}-0.0624 \\
(-1.64)\end{array}$ \\
\hline Length of stay & - & $\begin{array}{c}-0.0194 \\
(-1.38)\end{array}$ & $\begin{array}{l}-0.0188 \\
(-1.24)\end{array}$ & $\begin{array}{l}-0.0183 \\
(-1.12)\end{array}$ & $\begin{array}{l}-0.0092 \\
(-0.57)\end{array}$ & $\begin{array}{l}-0.0098 \\
(-0.69)\end{array}$ \\
\hline Disease category & - & - & $\begin{array}{l}0.1445 \\
(0.69)\end{array}$ & $\begin{array}{l}0.1727 \\
(0.75)\end{array}$ & $\begin{array}{c}0.2400 \\
(1.14)\end{array}$ & $\begin{array}{l}0.3273 \\
(2.48)\end{array}$ \\
\hline $\begin{array}{l}\text { Proportion of inpatients in tertiary medical } \\
\text { institutions }\end{array}$ & - & - & - & $\begin{array}{l}-0.1756 \\
(-1.41)\end{array}$ & $\begin{array}{c}-0.1859 \\
(-1.81)\end{array}$ & $\begin{array}{l}0.1116 \\
(0.26)\end{array}$ \\
\hline $\begin{array}{l}\text { Proportion of patients exported to } \\
\text { Shanghai }\end{array}$ & - & - & - & - & $\begin{array}{l}-0.3016 \\
(-164)\end{array}$ & $\begin{array}{l}-0.0753 \\
(-0.25)\end{array}$ \\
\hline Proportion of retirees & - & - & - & - & - & $\begin{array}{c}0.3549 \\
(0.99)\end{array}$ \\
\hline $\mathrm{R}^{2}$ & 0.8099 & 0.8256 & 0.8383 & 0.8398 & 0.8719 & 0.8987 \\
\hline
\end{tabular}


Table 5. Regression results on the effect of policy intervention on health insurance payments

\begin{tabular}{|c|c|c|c|c|c|c|c|c|}
\hline Variables & (1) & (2) & (3) & (4) & (5) & (6) & (7) & (8) \\
\hline Treat & $\begin{array}{c}-0.0435 \\
(-1.98)\end{array}$ & $\begin{array}{c}-0.0539 \\
(-1.96)\end{array}$ & $\begin{array}{c}-0.0952 \\
(-1.93)\end{array}$ & $\begin{array}{c}-0.1056 \\
(-1.79)\end{array}$ & $\begin{array}{c}-1852.798 \\
(-1.49)\end{array}$ & $\begin{array}{c}-0.0665 \\
(-1.00)\end{array}$ & $\begin{array}{c}-0.0525 \\
(-0.95)\end{array}$ & $\begin{array}{c}-0.0165 \\
(-0.19)\end{array}$ \\
\hline Post & $\begin{array}{c}0.8465^{* * *} \\
(26.39)\end{array}$ & $\begin{array}{c}0.7985^{* * *} \\
(8.67)\end{array}$ & $\begin{array}{c}0.7706^{* * *} \\
(7.90)\end{array}$ & $\begin{array}{c}0.75751^{* * *} \\
(7.00)\end{array}$ & $\begin{array}{c}0.8888^{* * *} \\
(11.68)\end{array}$ & $\begin{array}{c}0.8414^{* * *} \\
(11.05)\end{array}$ & $\begin{array}{c}0.8533^{* * *} \\
(12.04)\end{array}$ & $\begin{array}{c}0.8472^{* * *} \\
(10.88)\end{array}$ \\
\hline Treat*Post & $\begin{array}{c}0.0735 \\
(2.05)\end{array}$ & $\begin{array}{c}0.0701 \\
(2.11)\end{array}$ & $\begin{array}{c}0.0992 \\
(2.25)\end{array}$ & $\begin{array}{c}0.0966 \\
(2.14)\end{array}$ & $\begin{array}{c}0.0777 \\
(2.63)\end{array}$ & $\begin{array}{c}0.0610 \\
(2.12)\end{array}$ & $\begin{array}{c}0.0787 \\
(1.92)\end{array}$ & $\begin{array}{c}0.0376 \\
(0.43)\end{array}$ \\
\hline Length of stay & - & $\begin{array}{l}0.0132 \\
(0.62)\end{array}$ & $\begin{array}{c}0.0142 \\
(0.66)\end{array}$ & $\begin{array}{c}0.0148 \\
(0.65)\end{array}$ & $\begin{array}{c}0.0235 \\
(0.92)\end{array}$ & $\begin{array}{c}0.0229 \\
(0.76)\end{array}$ & $\begin{array}{c}0.0250 \\
(0.73)\end{array}$ & $\begin{array}{c}0.0226 \\
(0.55)\end{array}$ \\
\hline Disease category & - & - & $\begin{array}{c}0.2399 \\
(1.42)\end{array}$ & $\begin{array}{c}0.2714 \\
(1.39)\end{array}$ & $\begin{array}{l}0.3353 \\
(1.88)\end{array}$ & $\begin{array}{c}0.4102^{* * *} \\
(4.45)\end{array}$ & $\begin{array}{c}0.4381^{* * *} \\
(5.28)\end{array}$ & $\begin{array}{c}0.4509^{* * *} \\
(6.45)\end{array}$ \\
\hline Proportion of inpatients in tertiary medical institutions & - & - & - & $\begin{array}{l}-1957 \\
(-0.60)\end{array}$ & $\begin{array}{c}-0.2055 \\
(-0.43)\end{array}$ & $\begin{array}{c}0.0494 \\
(0.13)\end{array}$ & $\begin{array}{c}0.1015 \\
(0.30)\end{array}$ & $\begin{array}{c}0.2826 \\
(0.66)\end{array}$ \\
\hline Proportion of patients exported to Shanghai & - & - & - & - & $\begin{array}{c}-0.2866 \\
(-2.21)\end{array}$ & $\begin{array}{c}-0.0928 \\
(-0.57)\end{array}$ & $\begin{array}{c}-0.3850 \\
(-1.17)\end{array}$ & $\begin{array}{c}-0.1431 \\
(-0.24)\end{array}$ \\
\hline Proportion of retirees & - & - & - & - & - & $\begin{array}{l}0.3039 \\
(2.30)\end{array}$ & $\begin{array}{c}0.3901^{* *} \\
(3.98)\end{array}$ & $\begin{array}{c}0.4496^{* *} \\
(4.39)\end{array}$ \\
\hline Proportion of medical referral patients & - & - & - & - & - & - & $\begin{array}{c}-0.2521 \\
(-1.44)\end{array}$ & $\begin{array}{c}-0.1426 \\
(-0.48)\end{array}$ \\
\hline Co-payment & - & - & - & - & - & - & - & $\begin{array}{c}-0.2491 \\
(-0.73)\end{array}$ \\
\hline $\mathrm{R}^{2}$ & 0.9868 & 0.9882 & 0.9903 & 0.9934 & 0.9951 & 0.9962 & 0.9968 & 0.9969 \\
\hline
\end{tabular}


Table 6. Results of robustness check

\begin{tabular}{lllll}
\hline Variables & $\begin{array}{l}\text { Total cross- } \\
\text { region inpatient } \\
\text { visits }\end{array}$ & $\begin{array}{l}\text { Total medical expenditures } \\
\text { of cross-region healthcare }\end{array}$ & $\begin{array}{l}\text { Total amount of } \\
\text { health insurance } \\
\text { payments }\end{array}$ & $\begin{array}{l}\text { Medical } \\
\text { cost per- } \\
\text { visit }\end{array}$ \\
\hline \multirow{2}{*}{ Treat } & -0.1739 & -0.1833 & -0.0784 & -0.0094 \\
& $(-2.27)$ & $(-1.42)$ & $(-0.86)$ & $(-0.14)$ \\
Post & 0.2173 & 0.4108 & 0.4535 & 0.1935 \\
& $(2.39)$ & $(2.07)$ & $(4.79)$ & $(1.68)$ \\
Treat* ${ }^{*}$ post & 0.0692 & 0.0707 & 0.0563 & 0.0015 \\
Length of Stay & $(1.00)$ & $(0.57)$ & $(0.93)$ & $(0.03)$ \\
Disease category & 0.0479 & -0.0566 & -0.0607 & -0.1045 \\
Proportion of inpatients in & $(0.70)$ & $(-0.40)$ & $(-1.60)$ & $(-1.39)$ \\
tertiary medical institutions & 0.0931 & 0.2180 & 0.3041 & 0.1249 \\
$R^{2}$ & $(0.44)$ & $(0.43)$ & $-0.04)$ & $(0.39)$ \\
\hline
\end{tabular}

The increase in per capita income, the facilitation of transportation and the implementation of the policy of the immediate settlement of cross-region healthcare costs have improved the healthcare environment for patients. Undoubtedly, the removal of the "record-filing" or "pre-authorization" process further increases the number of cross-region inpatient visits by improving access to seeking medical treatment in other regions. According to the results, the number of patients that seeking healthcare services outside Wuxi increased 6.8 times since the implementation of the policy while the number of physician visits per patient declined to 1.7 from 2.4 times, which implied that the increase in inpatient visits was due to an increase in the number of patients seeking medical treatment outside the region of affiliation, rather than the frequency in the number of physician visits per person after the policy intervention. This suggested that patients' free movement policy could lead more patients to choose to receive healthcare services in other regions instead of the affiliated ones. Meanwhile, it is worth noting that the increase in total medical expenditures of cross-region was attributed to the rise in the number of cross-region patients as well because the medical cost per visit didn't show any noticeable changes. Furthermore, we compared the medical cost per visit of patients receiving healthcare services in other regions with local patients with the same demographic characteristics and diagnosis. It was found that the medical cost per visit of cross-region patients was higher than that of local patients. Therefore, the total medical expenditures for the entire region may grow up with the surge of cross-region patients after the removal of the "record-filing" process as well.

However, there is no evidence that the policy reform introduced in the fourth quarter of 2017 increased the total amount of health insurance payments for cross-region patients. Concerning the cross-region healthcare reimbursement policy in Wuxi, the local agency of administration used co-insurance as an effective tool to ensure the safety of the social health insurance funds. The co-payment rate for cross-region patients was $50 \%$ higher than that for patients seeking health services locally in Wuxi, which explains why the amount of health insurance payments was not affected by the intervention.

These findings have important policy implications for decision-making in the cross-region healthcare system, especially in China and the EU. According to the results, it is not recommended to remove the "record-filing" or "pre-authorization" process in regions with weak medical resources and health insurance funds. Notwithstanding, policymakers are increasingly designing policies that encourage patient choice. ${ }^{25}$ Giving patients the freedom to select medical care suppliers openly without the "record-filing" or "pre-authorization" process is typically the trend of policy reform according to a worldwide viewpoint. Thus, a higher co-payment rate for cross-region patients compared to patients who receive treatment in local medical institutions is highly recommended to reduce the financial risk of the health insurance funds effectively when patients move freely to seek healthcare services.

In addition, payment method reform and the implementation of the hierarchical medical system are two major trends to controlling the dramatic increase of cross-region medical expenses and to guide patients insured on schemes to seek cross-region medical treatment more reasonable from a long-term perspective. Firstly, post-payment methods like DRGs, case-based or value-based payment for cross-region patients are highly recommended to reduce the budget risk of health insurance funds. For patients receiving treatment in local regions, the medical cost is paid in prospective payment. While for cross-region patients, fee-for-service payment is still the main method in China, proving to be a major factor in the growth of medical expenses by inducing excessive medical treatment in crossregion healthcare. ${ }^{26,27}$ Secondly, the hierarchical medical system is required to be promoted to relieve pressure on high-level medical institutions. We also analyzed the patient flow of cross-region healthcare in Wuxi and Nantong and found that nearly $88.65 \%$ of the patients on medical schemes choose to be hospitalized in Shanghai, Beijing and 
other regions with high-quality medical resources and almost $90.78 \%$ of patients sought medical treatment in tertiary medical institutions. This indicated that the medical consultant principles in patient-importing regions and the allocation of the medical resources scheme in patient-exporting regions could be affected by the soar of cross-region patients. At the same time, the medical insurance department should strengthen the monitoring of the behavior of medical institutions where medical treatment is provided by examining and verification of medical expenses, to avoid the waste of medical resources.

The study has certain limitations. The samples selected in this article are patient-exporting cities while for the patient-importing cities, the impact of the policy is not estimated. In addition, the results reflect the short-term effects of patients' free movement without a record-filing process because the policy has not yet been fully implemented nationwide for a relatively long period. The results will be further enriched in future studies by expanding the sample size and data period. Moreover, the effects of patients' free movement on health quality and the healthcare system have not been evaluated, which were the other two major topics of patient mobility in cross-region healthcare. Evaluation of these changes are next steps in our research program.

\section{ACKNOWLEDGEMENTS}

The authors are grateful to the National Natural Science Foundation of China (Grant No. 72074220) and the National Healthcare Security Administration of China for supporting the research. And then sincerely thanks to the whole research group in China Pharmaceutical University for collecting and organizing data; our two anonymous reviewers and the editor for constructive feedback; and local experts for providing country-specific information.

\section{FUNDING}

This study was funded by the general program of National Natural Science Foundation of China: Study on the Influence of Medical Insurance Management and Payment Policy of Medical Treatment Beyond Pooling Regions on Recurrent Population's Health-Seeking Behavior, Health Outcome and Medical Expenditure (Grant No. 72074220).

\section{AUTHORSHIP CONTRIBUTIONS}

ZX and WX conceived the study and collected data. ZX and $\mathrm{MM}$ analyzed data and wrote the first draft of the manuscript, under the supervision of WX. WX reviewed and provided advice on the methods and conclusions. All three authors contributed to revising the final manuscript.

\section{COMPETING INTERESTS}

The authors completed the Unified Competing Interest form at http://www.icmje.org/disclosure-of-interest/ (available upon request from the corresponding author), and declare no conflicts of interest.

\section{CORRESPONDENCE TO:}

Wei Xu

School of International Pharmaceutical Business, China Pharmaceutical University, Nanjing, China.

xuzy0620@163.com

Submitted: December 31, 2020 GMT, Accepted: December 09, 2021 GMT 


\section{REFERENCES}

1. Andritsos DA, Tang CS. The impact of cross-border patient movement on the delivery of healthcare services. International Journal of Production Economics. 2013;145(2):702-712. doi:10.1016/j.ijpe.20 $\underline{13.05 .025}$

2. Peeters M. Free movement of patients: Directive $2011 / 24$ on the application of patients' rights in cross-border healthcare. Eur J Health Law. 2012;19(1):29-60. doi:10.1163/157180912×615158

3. Legido-Quigley H, Glinos I, Baeten R, McKee M. Patient mobility in the European Union. BMJ. 2007;334(7586):188-190. doi:10.1136/bmj.39086.4976 $\underline{39.68}$

4. Legido-Quigley H. Experiencing health care: the accounts of British pensioners migrating to Spain. London School of Hygiene and Tropical Medicine; 2010 .

5. Glinos IA, Baeten R. A literature review of crossborder patient mobility in the European Union. Observatoire social européen, Europe for patients. Published online 2006:115.

6. Hermesse J, Lewalle H, Palm W. Patient mobility within the European Union. The European Journal of Public Health. 1997;7(suppl 3):4-10. doi:10.1093/eurp ub/7.suppl 3.4

7. Legido-Quigley H, Nolte E. Assuring the quality of health care in the European Union: a case for action. World Health Organization; 2008. https://apps.who.in t/iris/handle/10665/107894

8. Legido-Quigley H, McKee M, Nolte E. Quality of Care, Patient Orientation, Information to Patients and Professionals. London School of Hygiene and Tropical Medicine; 2005. https://researchonline.lshtm.ac.uk/i d/eprint/8095

9. National Healthcare Security Administration. 2018 National Statistical Bulletin on the Development of the Basic Healthcare Security in China [EB/OL]. http://ww w.nhsa.gov.cn/art/2019/6/30/art 7 1477.html?from=si nglemessage \&isappinstalled $=0.2018$

10. Huang H. A three-dimensional analysis of immediate settlement of cross-region healthcare cost. Journal of China Social Security. 2019(3):47.
11. Del-Ama AJ, Koutsou AD, Moreno JC, de-losReyes A, Gil-Agudo n, Pons JL. Review of hybrid exoskeletons to restore gait following spinal cord injury. Journal of Rehabilitation Research and Development. 2012;49(4):497. doi:10.1682/jrrd.2011.0 $\underline{3.0043}$

12. Kowalska-Bobko I, Mokrzycka A, Sagan A, Włodarczyk WC, Zabdyr-Jamróz M. Implementation of the cross-border healthcare directive in Poland: How not to encourage patients to seek care abroad? Health Policy. 2016;120(11):1233-1239. doi:10.1016/ j.healthpol.2016.07.011

13. Sieveking K. ECJ Rulings on Health Care Services and Their Effects on the Freedom of Cross-Border Patient Mobility in the EU. Eur J Migr Law. 2007;9(1):25-51. doi:10.1163/138836407x179292

14. Azzopardi-Muscat N, Aluttis C, Sorensen K, Pace $\mathrm{R}$, Brand $\mathrm{H}$. The impact of the EU Directive on patients' rights and cross border health care in Malta. Health Policy. 2015;119(10):1285-1292. doi:10.1016/ j.healthpol.2015.08.015

15. De Angelis M. The Expansion of Patients' Rights in Europe: A New Perspective for Healthcare Abroad. Bulletin of the Transilvania University of Braşov, Series VII: Social Sciences and Law. 2014(1):111-120.

16. Van Nuffel P. Patients' Free Movement Rights and Cross-Border Access to Healthcare. Maastrich J Eur Comp Law. 2005;12(3):253-270. doi:10.1177/1023263 $\underline{\mathrm{x} 0501200304}$

17. Legido-Quigley H, Passarani I, Knai C, et al. Crossborder healthcare in the European Union: clarifying patients' rights. BMJ. 2011;342(jan172):d296-d296. $\underline{\mathrm{d}}$ oi:10.1136/bmj.d296

18. Kostera T. Europeanizing healthcare: cross-border patient mobility and its consequences for the German and Danish healthcare systems. Bruges Political Research Paper. 2008;7:38. http://aei.pitt.edu/7260/1/ wp7Kostera.pdf

19. Requejo MT. Cross-border healthcare in Spain and the implementation of the Directive 2011/24/EU on the Application of Patient's Rights in Cross-border Healthcare. Eur J Health Law. 2014;21(1):79-96. doi:1 $\underline{0.1163 / 15718093-12341305}$ 
20. Dawson D, Jacobs R, Martin S, Smith P. The impact of patient choice and waiting time on the demand for health care: results from the London Patient Choice project. Applied Economics. 2006;38(12):1363-1370. doi:10.1080/00036840500398 $\underline{810}$

21. Andritsos DA, Tang CS. Introducing competition in healthcare services: The role of private care and increased patient mobility. European Journal of Operational Research. 2014;234(3):898-909. doi:10.10 16/j.ejor.2013.11.022

22. Sepehri A, Sarma S, Oguzoglu U. Does the financial protection of health insurance vary across providers? Vietnam's experience. Social Science \& Medicine. 2011;73(4):559-567. doi:10.1016/j.socscime $\underline{\text { d.2011.06.009 }}$

23. Benoit K. Linear regression models with logarithmic transformations. London School of Economics. 2011;22(1):23-36. https://kenbenoit.net/a ssets/courses/ME104/logmodels2.pdf
24. McKee M, Belcher P. Cross border health care in Europe. BMJ. 2008;337:124-125. doi:10.1136/bmj.393 $\underline{98.456493 .80}$

25. Brekke KR, Gravelle H, Siciliani L, et. al. Patient choice, mobility and competition among health care providers. Health Care Provision and Patient Mobility. Published online 2014:1-26. doi:10.1007/978-88-47 0-5480-6_1

26. Eggleston K. Provider payment incentives: international comparisons. Int J Health Care Finance Econ. 2009;9(2):113. doi:10.1007/s10754-009-9065-3

27. Streveler DJ, Sherlock SM. Health management information systems for resource allocation and purchasing in developing countries. Published online 2004. http://hdl.handle.net/10986/13655 